\title{
Protease-catalyzed Synthesis of Oligo-L-glutamic Acid from L-Glutamic Acid Diethyl Ester
}

\author{
Keiichi Aso, Takashi Uemura and Yutaka ShIokawA \\ Department of Applied Biological Science, Science University of Tokyo, \\ Noda, Chiba 278, Japan
}

Received March 15, 1988

\begin{abstract}
A synthesis of L-glutamic acid oligopeptide from L-glutamic acid- $\alpha, \gamma$-diethyl ester hydrochloride is demonstrated by the use of papain and $\alpha$-chymotrypsin. An examination of this polymerization reaction by turbidimetry, a micro-biuret assay and gel chromatography showed that effective synthesis was achieved at $\mathrm{pH} 7 \sim 8.5$ in phosphate buffer at $25 \sim 35^{\circ} \mathrm{C}$ for both enzymes. It was revealed by gel chromatography that a higher molecular peptide fraction was accumulated during the reaction as a precipitate, which was determined to be peptides composed of 5 to 9 glutamic acid residues. When $100 \mathrm{~mm}$ of the substrate was incubated with $10 \mu \mathrm{M}$ of papain, more than an $80 \%$ overall reaction yield $(42 \%$ as a precipitate) was attained after $24 \mathrm{hr}$ of the reaction.
\end{abstract}

The usefulness of protease-catalyzed peptide bond synthesis has been demonstrated by a number of model studies, and has been applied to syntheses of some biologically active peptides ${ }^{11}$ and to the production of plasteins with improved nuturitional and functional properties. $^{2.3)}$ Proteases have also been known to synthesize water-insoluble polymers of $\alpha$ amino acids. In 1950 , Brenner et al. ${ }^{4.5)}$ found that $\alpha$-chymotrypsin produced di- or tripeptides from the isopropyl esters of methionine, threonine, phenylalanine and tyrosine. Dannenberg and $S_{\text {mith }}{ }^{6}$ later reported the synthesis of a phenylalanine oligomer by a protease from bovine lung. Sluyterman and Wijdenes ${ }^{7)}$ then investigated the kinetics of the papain-catalyzed polymerization of leucine methyl ester by a pH-stat. Recently, Anderson and Luisi, ${ }^{8}$ and Jost et al. ${ }^{9)}$ have shown that papain catalyzed the oligomerization of tyrosine methyl ester and methionine ethyl ester, respectively. In all these studies, polymerization degrees ranging from 2 to 11 were reported, but few of the products have been sufficiently isolated and characterized due to the difficulty in analyzing water-insoluble peptides which were also insoluble in many organic solvents. In addition, little attention has been paid to utilizing the enzymatic reaction as a preparative synthetic method for food materials in these previous studies.

L-Glutamic acid oligomers are known to have a brothy (umami) taste, ${ }^{10)}$ and are particularly interesting in the fields of food and medicinal chemistry, for they possess a bitter taste masking effect against many kinds of bitter compounds. ${ }^{11}$ It may also be possible to utilize these highly hydrophilic peptides as modifiers of functional properties by combining with other materials.

In this study, we have attempted to produce oligomers of L-glutamic acid by a one-step process, using proteolytic enzymes as the catalyst from a single substrate of L-glutamic acid- $\alpha, \gamma$-diethyl ester, and to characterize the features of their reactions.

\section{MATERIALS AND METHODS}

Materials. Proteases purchased and their suppliers were: trypsin (EC $3.4 .21 .4 ; 2 \times$ recrystallized), $\alpha$-chymotrypsin (EC 3.4.21.1; $3 \times$ recrystallized) and papain (EC 3.4.22.2; $2 \times$ recrystallized) from Sigma Chemical Co.; thermolysin (EC 3.4.24.4; $3 \times$ recrystallized) from Seikagaku Kogyo; and pepsin (EC 3.4.23.1; $1: 10,000$ product) from Nakalai Tesque Inc. All these enzymes were used without further purification. The molecular concentration of each enzyme 
was determined from its absorbance at $280 \mathrm{~nm}$ using the value listed in the literature. ${ }^{12)}$ The substrate, L-glutamic acid- $\alpha, \gamma$-diethyl ester hydrochloride (Glu-di-OEt), was prepared by the method of Boissonnas et al. ${ }^{13)} \mathrm{Re}$ crystallized Glu-di-OEt was checked by thin-layer chromatography on silica gel to give a single spot and characterized by NMR. All the other chemicals used were of reagent grade.

Enzymatic polymerization. Unless otherwise specified, the reaction mixture $(5 \mathrm{ml})$ containing $100 \mathrm{~mm}$ Glu-di-OEt, $10 \mu \mathrm{M}$ of each enzyme and $0.5 \mathrm{M}$ phosphate buffer ( $\mathrm{pH} 7.5$ ) was incubated at $25^{\circ} \mathrm{C}$ with gentle stirring. Glu-di-OEt was neutralized with I $\mathrm{N} \mathrm{NaOH}$ before preparing the reaction mixture. Dithiothreitol ( $1 \mathrm{~mm}$ final concentration) and EDTA (5 mM final concentration) were added to the reaction system containing papain. To examine the effects of $\mathrm{pH}$ and buffering agents on the reactivity, citrate, imidazole, Tris, HEPES and carbonate were used at various $\mathrm{pHs}$.

Assay of the polymerizing activity. At an appropriate interval, the increment of turbidity of the reaction mixture was measured at $550 \mathrm{~nm}$ in situ using a Klett-Summerson photoelectric colorimeter (Mode 1800-3). In addition, an aliquot of the reaction mixture was submitted to a microbiuret assay according to the method of Itzhaki and Gill. ${ }^{14)}$

Analysis of the reaction product by gel filtration. At an appropriate time during the reaction, a portion of the reaction mixture was treated with $1 \mathrm{~N} \mathrm{NaOH}$ for $15 \mathrm{~min}$ at $60^{\circ} \mathrm{C}$ to hydrolyze the ester linkages. After neutralization, the solubilized sample was applied to a column of Toyopearl HW-40 superfine $(1 \times 50 \mathrm{~cm}$, TOSOH $)$ and eluted with $0.1 \mathrm{~m}$ phosphate buffer $(\mathrm{pH} 7.0$ ) at a flow rate of $30 \mathrm{ml} / \mathrm{hr}$. The elution pattern was monitored at $220 \mathrm{~nm}$. The reaction mixture was diluted with 10 vol. of distilled water, and the water-insoluble product obtained by centrifugation (15 min at $3000 \mathrm{rpm}$ ) was then successively washed with distilled water on a membrane filter. The insoluble product was treated with $\mathrm{NaOH}$ and the resulting solution was submitted to gel filtration as already described.

Overall reaction yield. The overall yield of the polymerization reaction was calculated from the percentage decrease of the substrate determined as free glutamic acid.

Polymerization degree of the oligopeptides. Each peptide-containing fraction eluted from the Toyopearl column was pooled and re-chromatographed to provide a single peak. The ninhydrin reaction was applied to each fraction, and its $\alpha$-amino group content was determined prior to and after total acidic hydrolysis with $6 \mathrm{~N} \mathrm{HCl}$ at $110^{\circ} \mathrm{C}$ for $24 \mathrm{hr}$. From these data, an approximate polymerization degree for each peak was calculated.
Mass spectrometry. A solubilized precipitate fraction by alkali treatment was desalted by reversed-phase HPLC, and its molecular ion was determined by a JEOL mass spectrometer (JMS-DX303) fitted with a fast atom bombardment gun.

Amino acid analysis. Each of the peptide fractions obtained from the Toyopearl column was hydrolyzed with $6 \mathrm{~N} \mathrm{HCl}$ at $110^{\circ} \mathrm{C}$ for $24 \mathrm{hr}$ under reduced pressure. The resulting hydrolysate was analyzed by a HPLC system (TOSOH) fitted with a $\mathrm{MCI}$ gel $\mathrm{CK} 12 \mathrm{~F}$ column $(4.6 \times 130 \mathrm{~mm}$, Mitsubishi Chemical Ind.) and an on-line ninhydrin reactor (Nihon Seimitsu Kagaku Co.).

\section{RESULTS}

\section{Proteases for oligomerization}

In order to choose a suitable enzyme for synthesizing the oligopeptides from the five enzymes tested, we examined their turbidityforming and biuret-positive substance-forming activities at various $\mathrm{pHs}$, using two levels of enzyme concentration. As shown in Fig. 1, papain and $\alpha$-chymotrypsin showed much higher activities in the range of $\mathrm{pH} 7 \sim 8.5$; therefore. these two proteases were selected for further studies. The minor synthetic activity observed for trypsin was considered to have been due to chymotryptic activity contamination in this enzyme preparation. No signif-

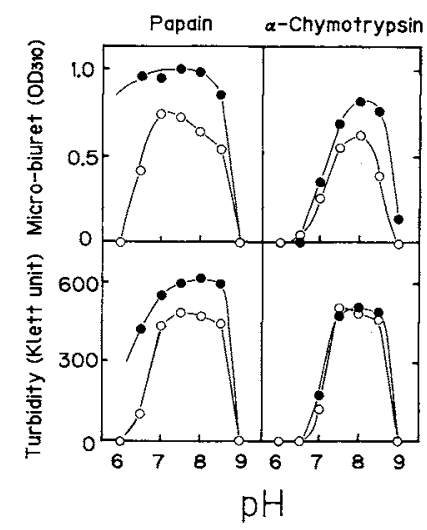

FIG. 1. pH Dependence of the Glu-oligopeptide Synthetic Activities of Papain and $\alpha$-Chymotrypsin.

The reaction mixture containing $10 \mu \mathrm{M}(\mathrm{O})$ or $100 \mu \mathrm{M}$ (๑) of each enzyme and $100 \mathrm{~mm}$ of Glu-di-OEt was incubated for $3 \mathrm{hr}$ at $25^{\circ} \mathrm{C}$ in phosphate buffer $(0.5 \mathrm{M}$, pH $6.0 \sim 8.5)$ or carbonate buffer $(0.5 \mathrm{M}, \mathrm{pH} 8.5 \sim 9.0)$. Their activities were followed by turbidimetry and the micro-biuret assay as described in the text. 
icant synthesis was observed for thermolysin or pepsin in the $\mathrm{pH} 2$ to 11 region. The addition of calcium ion to $\alpha$-chymotrypsin. trypsin and thermolysin did not affect the results, although this ion is known to enhance their activities.

Figure 2 shows the time courses of the turbidity increment and biuret-positive substance formation from Glu-di-OEt for these two enzymes at $\mathrm{pH} \mathrm{7.5}$. It indicates that the synthetic reaction was moderately fast compared to thermodynamically-controlled peptide synthesis, although it depended on the

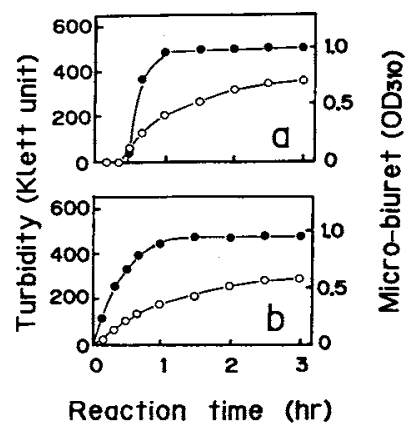

FIG. 2. Time courses of Papain- and $\alpha$-Chymotrypsincatalyzed Glu-oligopeptide Synthesis Followed by Turbidimetry ( $)$ and the Micro-biuret Assay $(O)$.

Phosphate buffer $(0.5 \mathrm{M}, \mathrm{pH} 7.5)$ was used for the reaction system, and the other experimental conditions were the same as those in Fig. 1.

a. papain, $10 \mu \mathrm{M} ; \mathrm{b}, \alpha$-chymotrypsin, $10 \mu \mathrm{M}$. enzyme concentration. Papain provided an obvious induction period at the lower enzyme concentrations, but after this period, exceeded $\alpha$-chymotrypsin in the reaction rate. The overall reaction yields after $3 \mathrm{hr}$ of the reaction were $51 \%$ and $43 \%$ for papain and $\alpha$-chymotrypsin, respectively.

\section{Characterization of the polymerization reaction and its products}

A reaction mixture containing $10 \mu \mathrm{M}$ papain and $100 \mathrm{~mm}$ Glu-di-OEt was analyzed at appropriate time intervals by gel filtration after hydrolyzing the ester linkages. Only two peaks were observed within $30 \mathrm{~min}$, but after that, the number of peaks increased with the progress of the reaction and finally, six distinguishable fractions were obtained. This profile did not change when the sample was applied to gel filtration using Toyopearl HW-50 superfine, which has a higher fractionation range than $\mathrm{HW}-40$. We applied the ninhydrin reaction to estimate the average chain length of the peptides in these fractions. By comparing the amino group content of each peptide with that of its hydrolysate, values of $1.2,2.0,3.0,3.7,6.5$ and 23.0 for peaks $A$ to $F$ designated in Fig. 4 were obtained, respectively. The hydrolysates of peaks $\mathrm{B}$ to $\mathrm{E}$ provided only glutamic acid by an amino acid analysis. We deduced an aver-

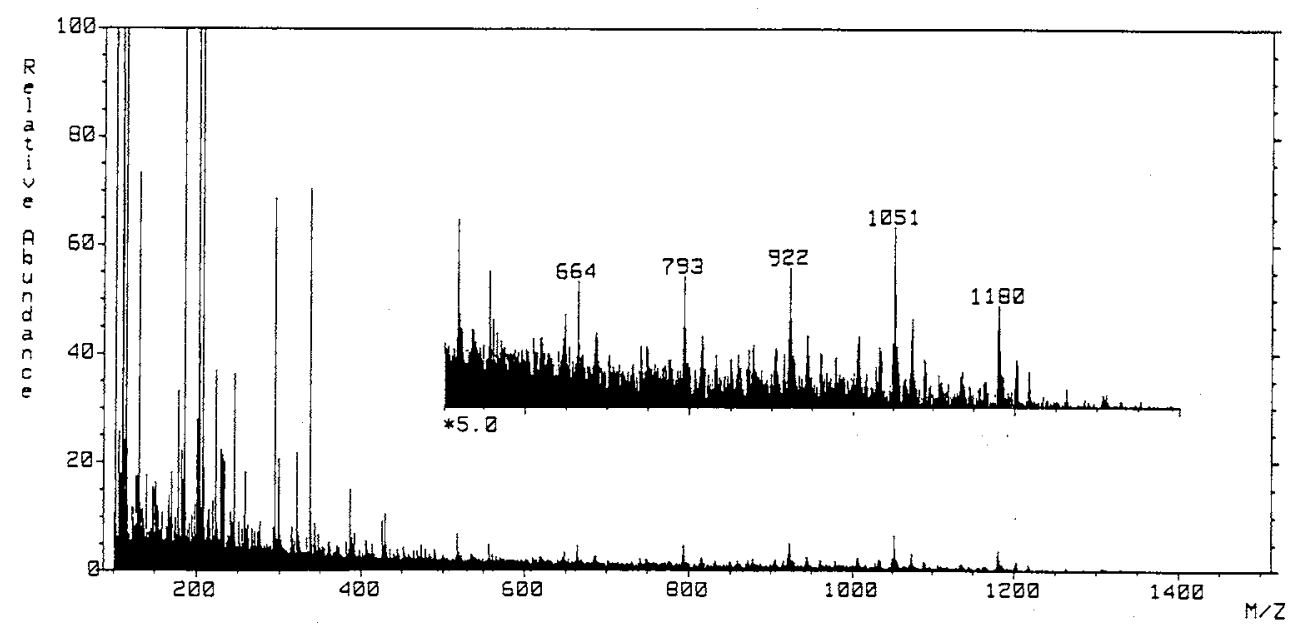

FIG. 3. FAB-Mass Spectrum of the Insoluble Fraction of the Product (de-esterified) Synthesized by Papain. 
age chain length of 1 for peak A, 2 for peak B, 3 for peak C, 4 for peak D and the higher molecular peptide mixture for peak E. Peak F was the enzyme peak, because it was observed at the beginning of the reaction and its amino acid composition agreed with that of the enzyme. As the insoluble reaction product obtained as a precipitate provided only peak $E$ after the alkaline treatment, this fraction was examined by mass spectrometry. Figure 3 shows the FAB-mass spectrum of $\left[\mathrm{MH}^{+}\right]$of the fraction in which the main molecular ions observed between $m / z 664$ and 1180 corresponded to penta- to nonapeptides. The analysis of the product synthesized by $\alpha$-chymotrypsin provided almost the same result already described, indicating that the solubility of the product may have been a dominant factor in its distribution.

The papain-catalyzed reaction was followed by analyzing the amount of remaining glutamic acid at different times. The time course of consumption of the substrate was very similar to the result from the micro-biuret assay, especially in the first $3 \mathrm{hr}$ of the reaction. The reaction appeared to be complete within $3 \mathrm{hr}$ when $10 \mu \mathrm{M}$ of papain is used, but a higher overall reaction yield, nearly $80 \%$, could be seen after $24 \mathrm{hr}$. At that time, the yield of the water-insoluble product was estimated to be $42 \%$ of the substrate, based on the glutamic acid content determined by an amino acid analysis. Thus, it has been confirmed that the micro-biuret assay was a convenient and fairly good method for analyzing the early stage of the reaction, although gel chromatography was a more useful means for detecting the products.

\section{Effect of the substrate concentration}

The dependence of the oligomerization reactions catalyzed by $10 \mu \mathrm{M}$ of papain and $\alpha$ chymotrypsin on the concentration of Glu-diOEt was studied in the range of 10 to $200 \mathrm{~mm}$. Negligible precipitation occurred within $3 \mathrm{hr}$ of the reaction when less than $30 \mathrm{~mm}$ of Glu-diOEt was used as the starting substrate, in spite of the minor formation of biuret-positive sub- stances. No synthesis was seen with either enzyme when the substrate concentration was below $10 \mathrm{~mm}$. To shift the reaction toward the synthesis of insoluble products, the reactive component had to be present at a concentration higher than $50 \mathrm{~mm}$. Marked accel-

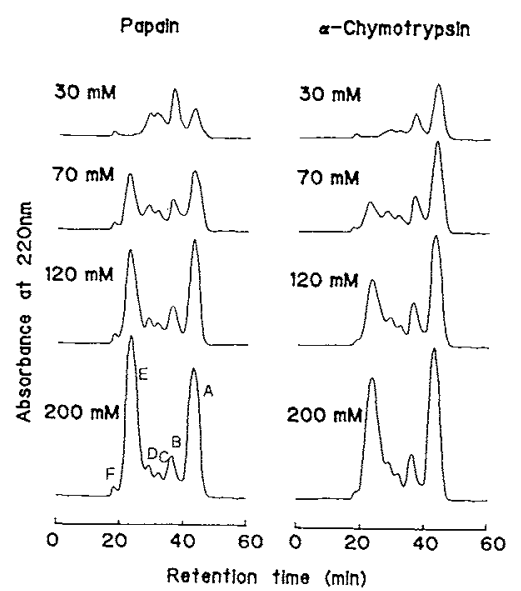

FIG. 4. Toyopear! HW-40S Column Chromatography of Glu-oligopeptide Synthesized by Papain and $\alpha$-Chymotrypsin at Different Substrate Concentrations.

The reaction was carried out using each enzyme $(10 \mu \mathrm{M})$ for $3 \mathrm{hr}$ at $25^{\circ} \mathrm{C}$ in phosphate buffer $(0.5 \mathrm{M}, \mathrm{pH} 7.5)$. See the text for the experimental conditions for gel chromatography.

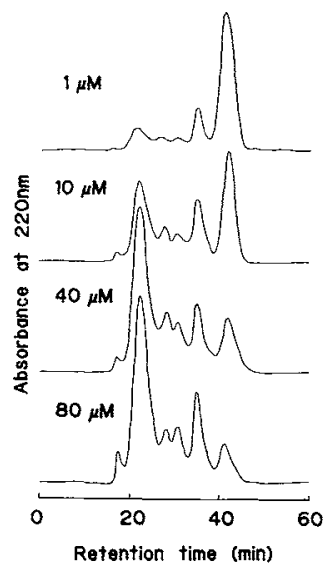

FIG. 5. Toyopearl HW-40S Column Chromatography of Glu-oligopeptide Synthesized by Papain at Different Enzyme Concentrations.

The reaction was carried out using $100 \mathrm{~mm}$ of Glu-di-OEt for $3 \mathrm{hr}$ at $25^{\circ} \mathrm{C}$ in phosphate buffer $(0.5 \mathrm{M}$. pH 7.5). See the text for the experimental conditions for gel chromatography. 
eration of synthesis proportional to the substrate concentration was seen up to $200 \mathrm{~mm}$ under the conditions used in this study. A comparison of the gel chromatograms of the reaction mixtures indicates that only high molecular products were accumulated with increasing substrate concentration after $3 \mathrm{hr}$ of the reaction, as shown in Fig. 4. The overall reaction yields were similar at higher substrate concentrations.

\section{Effect of the enzyme concentration}

The polymerization reaction in the presence of $100 \mathrm{~mm}$ Glu-di-OEt was studied with various concentrations of papain and $\alpha$-chymo-

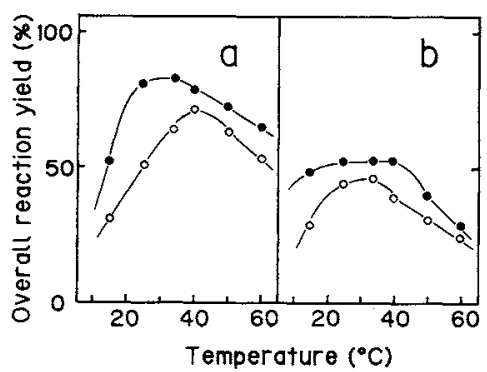

FIG. 6. Effects of Temperature on Papain(a)- and $\alpha$ Chymotrypsin(b)-catalyzed Glu-oligopeptide Synthesis.

The reaction mixture containing each enzyme $(10 \mu \mathrm{M})$ and Glu-di-OEt ( $100 \mathrm{~mm}$ ) was incubated for $3 \mathrm{hr}(\mathrm{O})$ and $24 \mathrm{hr}$

(O) at various temperatures in phosphate buffer $(0.5 \mathrm{M}$, $\mathrm{pH} 7.5$ ). The overall reaction yield was calculated from the consumption of the substrate as described in the text.

Table I. Effects of Some Buffering Agents on PAPAIN- AND $\alpha$-CHYMOTRYPSIN-CATALYZED GLU-OLIGOPEPTIDE SYNTHESIS

The reaction mixture containing each enzyme $(10 \mu \mathrm{M})$ and Glu-di-OEt ( $100 \mathrm{~mm}$ ) was incubated at $25^{\circ} \mathrm{C}$ for $24 \mathrm{hr}$ in each buffer solution $(0.5 \mathrm{M}, \mathrm{pH} 7.5)$. The overall reaction yield was calculated from the consumption of the substrate as described in the text.

\begin{tabular}{lcc}
\hline \multirow{2}{*}{ Buffering agent } & \multicolumn{2}{c}{ Overall reaction yield $(\%)$} \\
\cline { 2 - 3 } & Papain & $\alpha$-Chymotrypsin \\
\hline Phosphate & 82 & 53 \\
Phosphate-citrate & 73 & 51 \\
Imidazole & 66 & 47 \\
Tris-HCl & 57 & 45 \\
HEPES & 60 & 39 \\
\hline
\end{tabular}

trypsin. Below $10 \mu \mathrm{M}$ of each enzyme, the reaction depended on the enzyme concentration to a great extent, but little dependence was seen at higher concentrations. The reaction mixtures containing different amounts of papain were chromatographed to compare the product distribution (Fig. 5). An increase of papain concentration increased the overall reaction yield and enhanced the accumulation of the high molecular oligomer fraction. No significant accumulation of the smaller peptides was observed under these reaction conditions, and a similar result was obtained in the case of $\alpha$-chymotrypsin.

\section{Some factors affecting the polymerization reaction}

The reaction was carried out at temperatures between 15 and $60^{\circ} \mathrm{C}$, and the overall reaction yield was determined at 3 and $24 \mathrm{hr}$. As shown in Fig. 6, both papain and $\alpha$ chymotrypsin displayed practical temperature optima for polymerizing activity in the range of 25 to $35^{\circ} \mathrm{C}$ for a $24 \mathrm{hr}$ reaction, although papain exhibited its maximum activity at somewhat higher temperatures for a $3 \mathrm{hr}$ reaction. The various buffers for promoting the polymerization reaction were evaluated by comparing the overall reaction yield after $24 \mathrm{hr}$ of the reaction, as shown in Table I. The reaction proceeded most satisfactorily in phosphate buffer for both enzymes.

\section{DISCUSSION}

Since the elimination of the reaction product as an insoluble material is considered to be a thermodynamic driving force toward synthesis in enzyme-catalyzed peptide bond formation, ${ }^{1)}$ the diethyl ester of L-glutamic acid was chosen as the substrate which could easily be prepared from the amino acid and ethanol, both of which are used as food additives. A somewhat higher concentration of buffers compared to conventional enzyme reaction systems was employed in this study, because the progress of the reaction brought about a change in the $\mathrm{pH}$ of the system. Luisi and co-workers ${ }^{8.9)}$ have 
stressed that polymerization occurred under a much more restricted set of conditions, e.g., only within a small $\mathrm{pH}$ range of around 5.5 and in citrate buffer. However, the present study indicates that phosphate buffer is useful for the reaction at higher $\mathrm{pHs}$ betwee 7 and 8.5 for both enzymes employed here, although the reason is unclear.

Morihara and co-workers ${ }^{15,16)}$ have reported that the peptide bond formation induced by papain and $\alpha$-chymotrypsin was catalyzed through the formation of acyl-enzyme intermediates, and by a transesterification mechanism when $N$-acylated amino acid esters were used as carboxyl components. While Gludi-OEt could be employed as an effective nucleophilic agent during the glutamic acidenriched plastein synthesis by papain, ${ }^{2)}$ this amino acid ester has not yet been reported to be a typical substrate for papain and $\alpha$-chymotrypsin; and also, simple amino acid esters are known to be very poor substrates for transesterification by papain. ${ }^{17)}$ Therefore, the formation of acyl-enzyme intermediates from Glu-di-OEt and the enzymes is considered to be a key step governing the entire reaction process.

There was an apparent difference in the progress curves between papain- and $\alpha$-chymotrypsin-catalyzed reactions. The papaincatalyzed reaction exhibited a sigmoidal nature with a pronounced induction time in the early stage as observed by Sluyterman and Wijdenes, ${ }^{7}$ while a common downward curvature was obtained in the $\alpha$-chymotrypsincatalyzed reaction. These phenomena may be explained by different affinities of the amino acid ester and produced peptide esters to the substrate binding sites of the enzymes. It can also be expected that other mechanisms than transesterification e.g., transpeptidation or hydrolysis, would participate at a later stage of the reaction; therefore, further studies on the substrate specificity and the reaction mechanism remain to be investigated.

Changes in the composition of a reaction mixture during oligomerization have not been sufficiently followed nor the products charac- terized in previous studies because of considerable insolubility in water and in many organic solvents. Only in the case of methionine oligomers, ${ }^{9}$ oxidation of methionine to its sulfone could provide solubilized derivatives for analysis. In this study, de-esterification under alkaline conditions could convert each component in the reaction system to a fully soluble form. This also made it possible to analyze the characteristics of the reaction in detail and to utilize the products as water-soluble materials.

The present study was designed to evaluate the significance of protease-catalyzed oligomerization for the production of useful peptides. As the product distribution and yield can be expected to be controlled by the solubilities of products, by substrate concentration, and by such external conditions as buffers, $\mathrm{pH}$, and the presence of salts and organic solvents. the reaction systems for obtaining products with desirable properties and their applications are now under investigation.

\section{REFERENCES}

1) J. S. Fruton, Adv. Enzymol., 53, 239 (1982).

2) M. Yamashita, S. Arai, S. Kokubo, K. Aso and M. Fujimaki, J. Agric. Food Chem., 23, 27 (1975).

3) S. Arai, M. Yamashita and M. Fujimaki, Agric. Biol. Chem., 43, 1069 (1979).

4) M. Brenner, H. R. Müller and R. W. Pfister, Helv. Chim. Acta, 33, 568 (1950).

5) M. Brenner and R. W. Pfister, Helv. Chim. Acta, 34, 2085 (1951).

6) A. M. Dannenberg and E. L. Smith, J. Biol. Chem., 215, 55 (1955).

7) L. A. AE. Sluyterman and J. Wijdenes, Biochim. Biophys. Acta, 289, 194 (1972).

8) G. Anderson and P. L. Luisi, Helv. Chim. Acta, 62, 488 (1979).

9) R. Jost. E. Brambilla, J. C. Monti and P. L. Luisi, Helv. Chim. Acta, 63, 375 (1980).

10) M. Noguchi, S. Arai, M. Yamashita, H. Kato and M. Fujimaki, J. Agric. Food Chem., 23, 49 (1975).

11) M. Noguchi, M. Yamashita, S. Arai and $M$. Fujimaki, J. Food Sci., 40, 367 (1975).

12) G. D. Fasman (ed.), "Handbook of Biochemistry and Molecular Biology," 3rd Ed.. Protein, Vol. 2, CRC Press, Cleveland, 1976.

13) R. A. Boissonnas, S. Guttmann, P.-A. Jaquenoud and J.-P. Waller, Helv. Chim. Acta, 39, 1421 (1956).

14) R. F. Itzhaki and D. M. Gill, Anal. Biochem., 9, 401 (1961). 
15) T. Oka and K. Morihara, J. Biochem., 84, 1277 (1978).

16) K. Morihara and T. Oka, Biochem. J., 163, 531
(1977).

17) E. L. Smith and M. J. Parker, J. Biol. Chem., 233, 1387 (1958). 